\title{
Perceptions of Anti-obesity Medications among Spanish Personal Trainers
}

\author{
Iván Chulvi-Medrano ${ }^{1}$, Laura Masia-Tortosa ${ }^{2}$, Sergio Benito Hernandez ${ }^{3}$ \\ and Esteban Martínez Ballester ${ }^{4}$ \\ ${ }^{1}$ Sports Sciences. CSCS, NSCA-CPT, C/Camp de Morvedre, Algemes, Valencia, Spain \\ ${ }^{2}$ NSCA-CPT, C/Camp de Morvedre, Algemesí, Valencia, Spain \\ ${ }^{3}$ CSCS, NSCA-CPT. Sports Science. Sport Nutrition, C/ La Marina, Algemesí, Valencia, Spain \\ ${ }^{4}$ CSCS, NSCA-CPT. Physical Therapy, C/ Aguado, Perelló, Valencia, Spain
}

Correspondence should be addressed to: Iván Chulvi-Medrano; ivanchulvimedrano@gmail.com

Received 26 July 2013; Accepted 15 August 2013; Published 28 September 2013

Academic Editor: Pantelis Theodoros Nikolaidis

Copyright (C) 2013 Iván Chulvi-Medrano, Laura Masia-Tortosa, Sergio Benito Hernandez and Esteban Martínez Ballester. Distributed under Creative Commons CC-BY 3.0

\begin{abstract}
Physical activity, nutrition, and drug therapy are all important tools in this fight against premature illness and mortality in obesity population. Sometimes drug treatment for this epidemic is an often overlooked tool, although it may be an important option. The perception that personal trainers have about the effects of anti-obesity drugs may influence directly in the decision to use it in the obese population to lose weight. The objective of this article is to assess the perceptions of personal trainers regarding the use of obesity-fighting medications in addition to diet and exercise and compare with an American sample. A questionnaire based in a 7-point scale was administered to 31 experienced personal trainers in Spain who currently had obese clients (classified by OMS'values for BMI $\geq 30 \mathrm{Kg} / \mathrm{m}^{2}$ ). The results show $87 \%$ of the personal trainers who responded knew of at least one anti-obesity product, and only one third of them had customers undergoing drug treatment. The personal trainers perceived the importance of physical exercise as high (6.65), and they perceived the importance of drug treatment as comparatively low (3.13). They rated the importance of their own role in the battle against obesity as low (2.77), and believed that more education was required to better serve their obese clients (6.35). This data shows the need for greater training and education among personal trainers about weight loss strategies, anti-obesity medications, and physical exercise interventions. This situation needs to be addressed by private professional academies in their personal training courses.
\end{abstract}

Keywords: Body mass index, exercise, obesity, behavior, personal trainer.

\section{Introduction}

Obesity (as a disease) and its risk of comorbidities and mortality have reached epidemic levels, (Heredia et al., 2008; Villareal et al., 2005; Flegal et al., 2005; Dishman et al., 2004). Also an excess of body fat and body weight are associated 
with a decrease in physical fitness in young (Nikolaidis 2012a,b), adolescent, adult (Nikolaidis and Ingebrigtsen, 2013), and elderly (Villareal et al., 2005; Stewart et al., 2003) people. In Spain, $14.5 \%$ of the total population is considered obese (Aranceta et al., 2008). The behavioural changes necessary to battle obesity are multifaceted (Heredia et al., 2008), and given that exercise (lifestyle medication) is an important way to control body weight and dietary interventions (e.g. very low calorie and low fat diets) (Van Baak, 2013; Donelly et al., 2009; Stiegler and Cunliffe, 2006). Physical exercise recommendations are based on the dose-response relationship (Donelly et al., 2009; Rubio et al., 2007) and it's an important factor for weight control and avoid regain the weight lost (Jakicic, 2003). Thus, physical exercise in these cases should be designed, planned and supervised by a specialist. In this sense, personal trainers are important partners in the battle against obesity. Certificated personal trainer is a professional that instructs and trains persons in terms of safe and efficient exercises usually in individual conditions for increasing their physical fitness/performance and health (Roberts et al., 1997).

Personal trainers are recognized as having a high level of expertise in exercise prescription, athletics, sports, and health (Chulvi et al., 2007), as well as the specific topic of obesity (Chulvi et al., 2008), this professional profile has been developed extensively in the United States, being a growing movement in Spain. It has been reported that personal trainers can be effective in emphasizing the importance of improving one's body image and engaging in a healthy level of physical activity; both of which can lead to the client's expected bodily response and adaptation (Ratamess et al., 2008). Additionally, a personal trainer can exert great influence for instance, McClaran et al., (2003) demonstrated that the use of a personal trainer once per week improves adherence to and attitudes towards exercise. A previous report has shown a correlation between related factors (such as processes of change, decisional balance, and scheduling self-efficacy) to activity behaviour in female students that are utilizing personal trainers (Fischer et al., 2008).

A variable of great importance in the fight against weight gain and obesity in general is adherence to an exercise program. It is understood that people have difficulty with maintaining an active lifestyle (Knuth et al., 2009), and making time for physical activity is the most commonly reported barrier to being active among all population (Jakicic et al., 2003). The use of physical activity, nutrition and prescription medication can be an effective solution when exercise is not enough or is not utilized by the individual, (Ioannides et al., 2011; Rubio et al., 2007; Bellido et al., 2006).

However, there appears to be a need to increase awareness of anti-obesity medications in personal trainers (Lobb et al., 2008). In Spain there are two primary drugs prescribed for obesity, orlistat and sibutramine (Rubio et al., 2007; Bellido et al., 2006). The use of these drugs is suggested for people with a body mass index (BMI) between 29.9 and 37 who do not achieve appropriate results with the use of nutritional and behavioural therapies including physical activity (Rubio et al., 2007). As drugs may be an integral part of treatment in some cases of obesity, it is important to understand the perceptions that personal trainers have about these drugs because their advice can have a direct influence on the client's behaviour.

The aim of this study was to determine and to compare the perceptions of Spanish personal trainers regarding medications for the treatment of obesity with American personal trainers include in the research of Lobb et al., (2008).

\section{Methods}

Personal trainers can have great importance in the conducts and behaviours of obese individuals. In this sense, we have evaluated the perception of drugs and supplements for weight loss in Spanish personal trainers that are currently 
certified. Our hypothesis was the Spanish personal trainers have a bad perception of anti-obesity drugs. We have translated the questionnaire used previously by Lobb et al., (2008) and it has been administered via Internet to Spanish personal trainers. These personal trainers should be knowledgeable about medications for weight loss or personal training experience with subjects under pharmacological treatment.

\section{Subjects}

31 personal trainers certified by various national or international private academies participated in the study. The criterion for inclusion was currently working as a personal trainer, holding a valid certification as designated by NSCA
(National Strength and Conditioning Association), ACSM (American College of Sports Medicine), ANEF, FEDA and ORTHOS. The age of the respondents ranged between 18 and 35 years, with an average age (M) of 24.7 years and a standard deviation (SD) of 4.74 . $27.6 \%$ of the interviewees had two years of experience or less as a personal trainer, and $48.3 \%$ of the trainers had between two and three years of experience. The remaining $24.1 \%$ of the sample had four or more years of experience. Additionally, $6.5 \%$ of the respondents had no clients with a BMI greater than $30 \mathrm{~kg} / \mathrm{m}^{2}$ (obese), $38.7 \%$ had 1 to 4 obese clients, and $32.3 \%$ of the sample had 5 to 9 obese clients. Finally, the remaining $22.5 \%$ of the sample had more than 10 obese clients (see Figure 1).

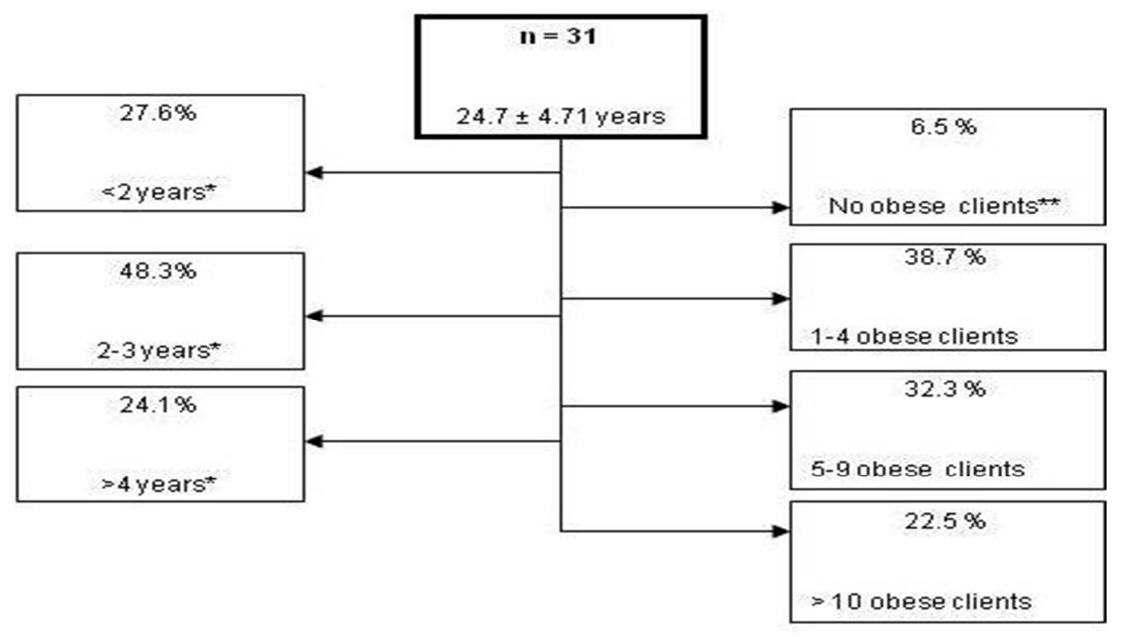

Figure 1: Descriptive Data of the Personal Trainers.

* Years of Experience as a Personal Trainer.

** Obesity Defined as BMI> $29.9 \mathrm{Kg} / \mathrm{M}^{2}$.

\section{Procedure}

The subjects were recruited by e-mail to participate in the study. The questionnaires were completed by certified personal trainers. During the process of filling out the questionnaire, one of the authors of the study was available online to answer questions for clarification purposes. Participation was voluntary and the respondents had to show proof that they were certified by one of the various associations of personal trainers.

\section{Questionnaire}

A translation of a questionnaire developed by Lobb et al., (2008) was utilized in the current study. The instrument consisted of 18 items assessing perceptions on a 7-item Likert-type scale ranging from strongly disagree [1] to strongly agree [7]. The survey also contained questions regarding age, years of experience as a personal trainer, the number of clients classified as obese, and questions related to knowledge about over-the-counter (OTC) and prescription anti-obesity medications. 


\section{Statistical Analysis}

The results were analysed using the statistical package SPSS (Version 15). A standard statistical methods for obtaining the frequency were used to obtain the mean as a measurement of the central trend and standard deviation as a measurement of dispersion.

\section{Results}

The results are reported in three sections. The first section addresses the medicinetaking behaviour of the clients as reported by the personal trainers. The second section addresses the knowledge of the personal trainers about OTC and prescription anti-obesity medications. The third section addresses the perceptions measured on the Likert-type scale, and compares the data to those reported in the previous study ${ }^{14}$, which used an American sample.

\section{Client Obesity and Drug Treatment}

Table 1 shows that each personal trainer had an average of 2.48 clients who reportedly were on prescription medications of any kind. $45.2 \%$ of the personal trainers did not have any client currently taking medications of any type. Approximately $75 \%$ of the personal trainers did not have clients taking prescription anti-obesity medications. Finally, the third section of the table shows that, on average, each personal trainer had 1.81 clients who had requested the trainer's opinion of anti-obesity medications. $64.5 \%$ of the trainers had not been asked about obesity fighting medications/supplements by their clients.

Table 1: Clients Obesity and Drug Treatment

\begin{tabular}{|c|c|c|c|c|c|c|c|c|}
\hline \multicolumn{3}{|c|}{$\begin{array}{l}\text { How many of your clients do you know } \\
\text { take any prescription medications? }\end{array}$} & \multicolumn{3}{|c|}{$\begin{array}{l}\text { How many of your clients do you know } \\
\text { take any prescription antiobesity } \\
\text { medications? }\end{array}$} & \multicolumn{3}{|c|}{$\begin{array}{c}\text { How many of your clients have asked } \\
\text { you what you think about these } \\
\text { medications? }\end{array}$} \\
\hline & Frecuency & $\%$ & & \multirow{2}{*}{ Frecuency } & \multirow{2}{*}{$\%$} & & Frecuency & $\%$ \\
\hline None & 14 & 45.2 & & & & None & 20 & 64.5 \\
\hline One & 4 & 12.9 & None & 23 & 74.2 & One & 4 & 12.9 \\
\hline Two & 6 & 19.3 & One & 6 & 19.4 & Two & 3 & 9.7 \\
\hline 3 to 5 & 3 & 9.7 & Two & 1 & 3.2 & 3 to 5 & 1 & 3.2 \\
\hline $\begin{array}{l}\text { More } \\
\text { than 5 }\end{array}$ & 4 & 12,9 & $\begin{array}{l}\text { More } \\
\text { than 2 }\end{array}$ & 1 & 3,2 & $\begin{array}{l}\text { More } \\
\text { than 5 }\end{array}$ & 3 & 9,7 \\
\hline \multirow[t]{3}{*}{ Total } & 31 & 100,0 & Total & 31 & 100,0 & Total & 31 & 100,0 \\
\hline & Mean (M) & SD ( \pm$)$ & & Mean (M) & SD ( $( \pm)$ & & Mean (M) & $\mathrm{SD}( \pm)$ \\
\hline & 2,48 & 4,56 & & 0,74 & 2,69 & & 1,81 & 4,83 \\
\hline
\end{tabular}

\section{Knowledge of Anti-obesity Medications}

$12.9 \%$ of the personal trainers were unaware of any OTC weight loss supplements (see Table 2). The remaining $87,1 \%$ knew of at least one product. One in four respondents knew of two products (25.8\%), and 6.5\% knew of three.
Regarding knowledge of prescription weight loss medications (see table 2), $22.6 \%$ did not know of any medications for the treatment of obesity. $51.6 \%$ knew of one medication while the remaining $25.8 \%$ knew of two medications. In total, $74.2 \%$ of the trainers were familiar with prescription weight loss medications. 
Table 2: Personal Trainer Awareness of Weight Loss Medications

\begin{tabular}{|c|c|c|c|c|c|}
\hline \multicolumn{3}{|c|}{$\begin{array}{l}\text { How many OTC weight loss medications are you } \\
\text { familiar with }\end{array}$} & \multicolumn{3}{|c|}{$\begin{array}{l}\text { How many prescription weight loss medications } \\
\text { are you familiar with? }\end{array}$} \\
\hline & Frequency & Percentage & & \multirow{2}{*}{ Frequency } & \multirow{2}{*}{ Percentage } \\
\hline None & 4 & 12.9 & & & \\
\hline One & 17 & 54.8 & None & 7 & 22.6 \\
\hline Two & 8 & 25.8 & One & 16 & 51.6 \\
\hline Three & 2 & 6,5 & Two & 8 & 25,8 \\
\hline Total & 31 & 100,0 & Total & 31 & 100,0 \\
\hline
\end{tabular}

\section{Perceptions Regarding the Procedures for Weight Loss}

In Table 3 we present the average response obtained for each item on the battery. The first column shows the results obtained by Lobb et al., (2008) which will be referred to as Lobb's Group (LG) $(n=23)$. The second column shows the results of the entire sample of the present study ( $\mathrm{n}=31)$ which will be referred to as the total group (TG). Finally, the last column shows the results for the subset of trainers who knew of at least one weight loss medication $(n=24)$, similar to the procedure used by Lobb et al., ${ }^{14}$ will be referred to as the knowledge group (KG).

\section{Table 3: Perceptions Regarding the Procedures for Weight Loss}

\begin{tabular}{|c|c|c|c|}
\hline \multirow{3}{*}{ ITEMS } & \multicolumn{3}{|c|}{ Mean (M) } \\
\hline & \multirow{2}{*}{\begin{tabular}{c|c|} 
Lobb \\
$\mathbf{n}=\mathbf{2 3}$
\end{tabular}} & \multicolumn{2}{|c|}{ Chulvi et al. } \\
\hline & & $\mathbf{n = 3 1}$ & $n=24$ \\
\hline 1.- I think diet is an important component of a weight loss program & 6,67 & 6,55 & 6,58 \\
\hline 2.- I think exercise is an important component of a weight loss program & 7,00 & 6,65 & 6,67 \\
\hline 3.- I think medication use is an important component of a weight loss program & 1,96 & 3,10 & 2,96 \\
\hline 4.- Some clients could not succeed in weight loss without OTC medications & 1,75 & 1,29 & 1,29 \\
\hline 5.- Some clients could not succeed in weight loss without prescription medications & 2,63 & 3,03 & 2,96 \\
\hline 6.- Obesity is a disease for which medications are important treatments & 2,71 & 2,23 & 2,29 \\
\hline 7.- Trainers should assess clients for their potential need for antiobesity medications & 2,42 & 5,58 & 5,58 \\
\hline $\begin{array}{l}\text { 8.- Trainers that recommend supplements \& OTC drugs should be concemed about drug } \\
\text { interactions }\end{array}$ & 6,67 & 6,52 & 6,58 \\
\hline $\begin{array}{l}\text { 9.- Using a personal trainer is far more important than using prescription medications as } \\
\text { it comes to weight loss }\end{array}$ & 6,46 & 2,77 & 3,00 \\
\hline $\begin{array}{l}\text { 10.- Clients that use of prescription medications are more likely to lose weight than those } \\
\text { that do not }\end{array}$ & 2,96 & 3,13 & 2,96 \\
\hline $\begin{array}{l}\text { 11.- People overestimate the value of prescription medications relative to exercise, diet } \& \\
\text { lifestyle changes }\end{array}$ & 6,08 & 5,84 & 5,96 \\
\hline $\begin{array}{l}\text { 12.- In clients that choose } \mathrm{Rx} \text { medications, I try to illustrate that } \mathrm{Rx} \text { medications are less } \\
\text { of a solution than diet \& exercise }\end{array}$ & 3,00 & 5,97 & 5,92 \\
\hline $\begin{array}{l}\text { 13.- Other personal trainers do not recommend the use of weight loss medications or } \\
\text { supplements }\end{array}$ & 3,30 & 6,06 & 5,96 \\
\hline 14.- I am concemed about the side effects of prescription medications & 6,71 & 6,06 & 6,04 \\
\hline
\end{tabular}

\section{Discussion}

The primary objective of our study was to compare the perceptions regarding weight loss medications among a sample of Spanish personal trainers with those obtained by Lobb et al., (2008). Thus, the discussion is based on a comparison of the current study and the American study.

The initial sample in the previous report was comprised of 43 personal trainers. The perceptions were obtained from a subsample of 23 participants. The criterion for inclusion in the subsample was to have some knowledge about anti-obesity drugs. In our case, from the total sample of 31 participants, 24 met this criterion. This number of subjects is not high thus represented a powerful study limitation, additionally, questionnaire were not conducted at random due to insufficient sample.

The personal trainers surveyed attributed great importance to diet and exercise as 
components of weight-reduction programs. These results match those of Lobb et al., (2008). In both studies, personal trainers did not give undue weight to medication in the successful treatment of obesity.

Regarding physical exercise and diet as weight-loss methods, the data from Lobb's survey had a different trend $(\mathrm{M}=3.00)$. That is, in our study, personal trainers informed their clients that anti-obesity drugs are less important than physical exercise and diet for reducing weight. In other words, they trivialized the importance of drugs. Trainers surveyed by Lobb et al., (2008) tended not to do so.

Answers to items related to the importance of personal trainers in achieving weight loss indicate that trainers from neither sample emphasized medication as a component of a weight-reduction program.

Personal trainers believed that clients and people in general, tend to rate medicine as more important than a personal trainer in reducing body weight. In both studies, trainers believed that people in general, and their clients in particular, overestimate the effectiveness of anti-obesity drugs.

Personal trainers surveyed by Lobb et al., (2008), believed that weight loss is achieved better with a personal trainer than prescription medication. The Spanish personal trainers did not grant themselves as much importance in the treatment of obesity. This could be related to the fact that personal training is a relatively new concept in Spain, or perhaps that the educational programs conducted by private institutions in Spain do not adequately train their students.

The personal trainers of our study agreed that they are capable of assessing the need of the clients for drug treatment. American trainers were more likely to disagree with this point, Lobb et al., (2008). This disagreement could be due to stronger restrictions among American personal trainers when dealing with medical issues in their clients.
The personal trainers from both studies believed that the consumption of drugs and supplements have side effects and, as personal trainers, were generally opposed to such consumption. In both studies respondents were aware of the need to receive more training on issues like obesity, drug treatments, and their interaction with exercise (Lobb et al., 2008).

The current data show that among personal trainers, there is a tendency to place a great deal of emphasis on exercise and diet, leaving the use of anti-obesity drugs as a last resort. According to McClaran et al., (2003), this may facilitate the promotion of healthy lifestyles including physical activity and healthy nutrition.

For the last item the average score obtained represents the desire to know more about anti-obesity drugs and interactions with the physical exercise, this data is very similar that reported by Lobb et al., (2008), and shown the growing interest for increasing the number of qualities and competencies that an effective exercise leader will be required, Melton et al., (2010).

The most obvious limitation of the study is its small number of participant in this study, thus, the number of cases is too limited for broad generalizations and the conclusions must be interpreted with caution.

In conclusion, the perception of trainers is that clients overestimate the effectiveness of anti-obesity drugs. Personal trainers believe that drugs and supplements have side effects. They also believe that they need more training regarding obesity, drug treatments, and their interaction with exercise. Personal trainers are aware of their role in fighting obesity, therefore institutions and training academies should require more specific training on this topic. Personal trainers can play a very important role in the weight loss process by creating personalized exercise regimens. Specific 
education for personal trainers should include the importance of physical exercise, dietary recommendations, and medical options for weight loss, as well as when such options are advisable, how they work, and the possible negative side effects.

\section{References}

Aranceta, J., Pérez, C., Serra, L. L., Ribas, L., Quiles, J., Vioque, J., Tur, J., Mataix J, Llopis, J., Tojo, R., Foz, M. \& Collaborative Group for the Study of Obesity in Spain (2003). "Prevalence of Obesity in Spain: Study of the Results SEEDO 2000 Study," Medicina Clinica,120(16):608-12.

Bellido, D. (2006). 'The Overweight Patient: A Practical Guide for Action in Primary Care,' Revista Espa-ola de Obesidad, 4(1):33-44.

Chulvi, I., Heredia, J. R., Isidro, F. \& Masiá, L. (2008). "The Personal Trainer and Obesity," Portaldeportivo.Cl [Internet] No6 Mayo-Junio Available http://www.culturafitness.com/document s/entrenador_personal_y_obesidad.pdf

Chulvi-Medrano, I., Pomar-Puig, R., Heredia-Elvar, J. R. \& Colado, J. C. (2007). "Personalized Physical Training in Improving Health and Athletic Performance," www.efdeportes.com [internet] $12 \quad$ (112) available http://www.efdeportes.com/efd112/elentrenamiento-fisico-personalizado.htm.

Dishman, R. K., Washburn, R. A \& Heath, G. W. (2004). Physical Activity Epidemiology, Human Kinetics Champaign, Illionois, USA.

Donnelly, J. E., Blair, S. N., Jakicic, J. M., Manore, M. M., Rankin, J. W. \& Smith, B. K. (2009). "Appropriate Physical Activity Intervention Strategies for Weight Loss and Prevention of Weigth Regain for Adults," Medicine and Science in Sports and Exercise, 41(2):459-71.

Fischer, D. V. \& Bryan, J. (2008). "Effect of Certified Personal Trainer Services on Stage of Exercise Behaviour and Exercise Mediators in Female College Students,"
Journal of American College Health, 56(4): $369-76$.

Flegal, K. M, Graubard, B. L., Williams, D. F. \& Gail, M. H. (2005). "Excess Deaths Associated with Underweight, Overweight, and Obesity," JAMA, 293(15):1861-7.

Heredia, J. R., Isidro, F., Roig, J. L., Chulvi, I., Moral, S. \& Molins, A. (2008). 'Overweight / Obesity, Physical Activity and Health: Intervention through Fitness Programs,' Wanceulen, Sevilla, Espa-a.

Ioannides-Demos, L. L., Picenna, L. \& Mcneil, J. J. (2011). "Pharmacotherapies for Obesity: Past, Current, and Future Therapies," Journal of Obesity, 2011:179674.

Jakicic, J. M. (2003). "Exercise in the Treatment of Obesity," Endocrinology and Metabolism Clinics of North America, 32(4):967-980.

Jakicic, J. M. \& Gallagher, K. I. (2003). "Exercise Considerations for the Sedentary Overweight Adult," Exercise and Sport Science Reviews, 31(2):91-5.

Knuth, A. G. \& Hallal, P. C. (2009). "Temporal Trends in Physical Activity: A Systematic Review," Journal of Physical Activity and Health, 6(5):548-59.

Lobb, L. R., Lobb, W. B. \& Hallam, J. S. (2008). "Perceptions of Antiobesity Medications among Personal Trainers," Journal of Strength and Conditioning Research, 22(2):485-489.

McClaran, S. R. (2003). "The Effectiveness of Personal Training on Changing Attitudes towards Physical Activity," Journal of Sports Science and Medicine, 2:10-4.

Melton, D. I., Dail, T. K., Katula, J. A. \& Mustian, K. M. (2010). "The Current State of Personal Training: Managers' Perspectives," Journal of Strength and Conditioning Research, 24 (11):3173-3179.

Nikolaidis, P. T. (2012). "Association between Body Mass Index and Body Fat Per Cent are associated with Decreased Power 
Output in Soccer Players," Central European Journal of Medicine, 7(6):783-9.

Nikolaidis, P. T. (2012). "Physical Fitness Is Inversely Related with Body Mass Index and Body Fat Percentage in Soccer Players Aged 16-18 Years," Medical Review (Medicinski Pregled), 65(11-12):470-475.

Nikolaidis, P. T. (2013). "Body Mass Index and Body Fat Percentage are associated with Decreased Physical Fitness in Adolescent and Adult Female Volleyball Players," Journal of Research in Medical Sciences, 18(1):22-6.

Nikolaidis, P. T. \& Ingebrigtsen, J. (2013). 'The Effect of Excess Body Mass on Physical Fitness in Adolescent and Adult Male Handball Players,' Indian Journal of Physiology and Pharmacology, 57(4).

Ratamess, N. A., Faigenbaum, A. D., Hoffman, J. R. \& Kang, J. (2008). "SelfSelected Resistance Training Intensity in Healthy Women: The Influence of a Personal Trainer," Journal of Strength and Conditioning Research, 22(1):103-11.

Roberts, S. (1997). 'The Business of Personal Training,' Human Kinentics, Champaing, Ilionois, USA.

Rubio, M. A., Salas-Salvadó, J. \& Barbany, M. (2007). 'Consensus SEEDO 2007 for the Assessment of Overweight and Obesity and the Establishment of Criteria for Therapeutic Intervention,' Revista Espa-ola de Obesidad, 7-48.

Stewart, K. J., Turner, K. L., Bacher, A. C., Deregis, J. R., Sung, J., Tayback, M. \& Ouyang, P. (2003). "Are Fitness, Activity, and Fatness associated with Health-Related Quality of Life and Mood in Older Persons?," Journal of Cardiopulmonar Rehabilitation, 23 (2): 115-121.

Stiegler, P. \& Cunliffe, A. (2006). "The Role of Diet and Exercise for the Maintenance of Fat-Free Mass and Resting Metabolic Rate During Weigth Loss," Sports Medicine, 2006; 36 (3): 239-262.
Van Baak, M. A. (2013). "Nutrition as a Link Between Obesity and Cardiovascular Disease: How Can We Stop the Obesity Epidemic?," Thrombosis and Haemostasia.

Villareal, D. T., Apovian, C. M., Kushner, R. \& Klein, S. (2005). "Obesity in Older Adults: Technical Review and Position Statement of the American Society for Nutrition and NAASO the Obesity Society," Obesity Research 2005; 13: 1849-1863. 